\title{
Cosmetic surgery on YouTube: a content analysis of East Asian blepharoplasty-related videos in South Korea
}

\author{
Kyoung-Min Kang ${ }^{1} \mathbb{D}$, Yongil Shin, $\mathrm{MD}, \mathrm{PhD}^{2,3}\left[\mathbb{D}\right.$, Kyoungjin Kang, $\mathrm{MD}, \mathrm{PhD}^{4}(\mathbb{D}$ \\ ${ }^{1}$ Korean College of Cosmetic Medicine (KCCS), Busan, Rep. of Korea, ${ }^{2}$ Department of Rehabilitation Medicine, Pusan National University School \\ of Medicine, Yangsan, Rep. of Korea, ${ }^{3}$ Research Institute for Convergence of Biomedical Science and Technology, Pusan National University \\ Yangsan Hospital, Yangsan, Rep. of Korea, ${ }^{4}$ Seoul Cosmetic Surgery Clinic, Busan, Rep. of Korea
}

\begin{abstract}
Background: As social media gets commonly used worldwide, there is an enormous amount of information available on YouTube. While cosmetic surgery-related content in English on YouTube has been studied priorly, those in Korean have not been explored.

Objective: The purpose of this study is to analyze the status quo of aesthetic-related content, specifically on East Asian blepharoplasty, on YouTube in South Korea.

Methods: The 535 returned videos for the search term 'SSangkkeopul Susul', the Korean word for East Asian blepharoplasty, were collected on July 9, 2020, and classified by types of content and uploader, view counts, and length of videos, then, analyze, using Excel (Microsoft).

Results: Fifty five percent of collected videos was to provide surgery-related information, and $20.0 \%$ was to show patient experience. Also, $76.8 \%$ of the videos were uploaded by medical doctors or clinics, while $13.6 \%$ was uploaded by personal accounts and $5.4 \%$ by content creators. The most common type of content was surgery-related information uploaded by medical doctors and clinics, followed by patient experience posted by personal channels. The average length of all videos was 4 minutes 46 seconds. However, among the ten most-viewed videos, only one was uploaded by medical doctor and the others were uploaded by nonmedical personnel.

Conclusion: Medical doctors have a quantitatively huge influence on cosmetic surgery-related content on YouTube in Korea, which leads the information in those videos more reliable. However, due to the lack of clarity in relevant regulations and the absence of constant monitoring, potentially harmful or sensitive contents are still available on YouTube. Thus, preventative measures at the governmental level are needed.
\end{abstract}

Keywords: double eyelid surgery; East Asian blepharoplasty; Medical Service Act; YouTube

\section{Introduction}

With the advancement of technology, many people are spending a considerable amount of time on social media to interact with others and gather information. YouTube is one of the most commonly used video-sharing platforms worldwide.
In South Korea, it is reported to be one of the most used apps by Android users in 2019 [1]. According to the WISE APP, an app analytics firm in South Korea, more than 33.6 million people used the YouTube app for an average of 25.666 hours in June 2020 [2].

According to the 2020 Netizen Profile Research (NPR) re-

Received September 29, 2020; Accepted November 3, 2020

Corresponding author: Kyoungjin Kang

E-mail: safikccs@pascal-world.com

This is an Open Access article distributed under the terms of the Creative Commons Attribution Non-Commercial License (http://creativecommons.org/licenses/by-nc/4.0), which permits unrestricted non-commercial use, distribution, and reproduction in any medium, provided the original work is properly cited.

Copyright ( 2020 Korean Society of Korean Cosmetic Surgery and Medicine (KSKCS \& KCCS). 
port of NAS Media (Seoul, Korea), watching of online videos is a generalized activity, which people of all age groups (10-60 years) engage in. A total of $94.6 \%$ people across all age groups are reported to watch online videos in Korea. Moreover, 99.3\% of people in their 20s are reported to watch online videos in South Korea [3]. Thus, its impact on the delivery of information is indisputable.

However, one of the problematic aspects of social media is that, since everyone has access to all posts uploaded by a person, and there are numerous posts by various groups of people, it becomes difficult to determine whether the posted information is credible. This is especially true for videos related to certain fields that require professional knowledge. Thus, it is crucial to distinguish the content providers in order to determine the reliability of content.

Because of the increasing number of people who use YouTube on a daily basis, many industries are utilizing it as a social media platform to promote their businesses. A number of studies have been conducted on YouTube content and its influence [4-6]. Although several studies have been conducted on plastic surgery-related YouTube content, there seem to be very few that have analyzed non-English content. Most of the studies written in English seem to exclude the plastic surgery-related videos made in other languages.

Various studies have analyzed and assessed plastic surgeryrelated videos on YouTube. Some of them have found these videos to be uninformative or unreliable when analyzed in English $[4,5]$. Further, the aesthetic surgery-related content in Korean has not been analyzed by any research study.

South Korea is renowned for its high demand for aesthetic surgery. The New Yorker in 2016 described South Korea as "the world's aesthetic-surgery capital." The most recent survey conducted by Gallup Korea in 2020 found that approximately $25 \%$ to $31 \%$ of Korean women in their 20 s and 30 s respectively claimed to have undergone aesthetic surgery [7]. The most commonly performed type of aesthetic surgery in South Korea is the "East Asian blepharoplasty," often called "double eyelid surgery." A survey of 574 South Korean women found that $17.247 \%$ of them have undergone this type of surgery. The survey further found $2.787 \%$ of Korean women wishing to undergo this surgery in the future [7].

Having carried out an analysis of the most prevalent plastic surgery-related content available on YouTube, Almarghoub et al. [4] found that YouTube is not sufficiently utilized by plastic surgeons. However, they claimed that there is a potential opportunity to advance the industry. In South Korea, many busi- nesses have for a consider time been using YouTube as a tool to communicate with the public. Thus, an analysis of how the Koreans use YouTube in educating and promoting aesthetic surgery-related information can serve as a beneficial example to develop aesthetic surgery-related content in other regions and languages.

While there is a notable amount of aesthetic surgery-related content on YouTube, there has not been any study that has analyzed it in Korean. Thus, this study attempts to shed light on the status quo of aesthetic surgery-related content in South Korea.

\section{Materials and methods}

The data were collected on YouTube on July 9, 2020 with a search term "SSangkkeopul Susul," a Korean word for East Asian blepharoplasty, the most commonly performed aesthetic surgery in South Korea. "Upload date" and "this year" were the options selected in default setting. A total of 545 returned videos were reviewed from July 9 to July 30, 2020. Duplicated videos, non-Korean videos, and videos removed during the review period were excluded; however, no videos were excluded on the basis of their length and quality of content. A number of elements of each of the videos were collected and reviewed, including the number of views, uploaded date, and the length of the videos.

First, the videos were arranged according to the type of content, authorship, number of views, and length. The types of content were further characterized by the alternatives to surgeries, beauty tips, pre- and postoperative portrait photographs, commercial, entertainment, surgery-related information, insurances, live procedures, medical malpractice lawsuits, opinions, patient experiences, postoperative instructions, surgeon's life stories, TV programs, and others. Authorship criteria were categorized into medical doctor/clinic, oriental medicine doctor, personal channel, content creator, and others. Microsoft Excel was used to collect and analyze the data.

\section{Results}

A total of 535 videos were evaluated in the final analysis. Of them, 294 videos (55.0\%) aimed to provide surgery-related information, including information pertaining to the type and process of surgery, and what to consider before surgery (Table 1). A total of 107 videos (20.0\%) were regarding patient experiences, 38 videos $(7.1 \%)$ were regarding pre- and postoperative portrait photographs, 24 videos $(4.5 \%)$ were regarding post- 
operative instructions, and 23 videos (4.3\%) were regarding entertainment. The remaining categories of videos were as follows: commercial (1.9\%); alternatives to surgery (1.7\%); beauty tips $(0.9 \%)$; TV programs $(0.9 \%)$; others $(0.9 \%)$; live procedures $(0.7 \%)$; opinion $(0.7 \%)$; surgeons' life stories $(0.6 \%)$; insurance (0.4\%); and medical malpractice lawsuits (0.4\%) (Table 1).

Of the 535 videos uploaded, 411 (76.8\%) were uploaded by medical doctors and clinics, $73(13.6 \%)$ by personal channels, and 29 (5.4\%) by content creators (Fig. 1).

This study reveals that around half of the Asian blepharoplas-

Table 1. Types of content

\begin{tabular}{|lc|}
\hline \multicolumn{1}{c}{ Content type } & No. of videos (\%) \\
\hline Surgery-related information & $294(55.0)$ \\
\hline Patient experience & $107(20.0)$ \\
\hline Pre- and postoperative portrait & $38(7.1)$ \\
\hline Postoperative instruction & $24(4.5)$ \\
\hline Entertainment & $23(4.3)$ \\
\hline Commercial & $10(1.9)$ \\
\hline Alternatives to surgery & $9(1.7)$ \\
\hline Beauty tip & $5(0.9)$ \\
\hline TV programme & $5(0.9)$ \\
\hline Others & $5(0.9)$ \\
\hline Live procedure & $4(0.7)$ \\
\hline Opinion & $4(0.7)$ \\
\hline Surgeon's life story & $3(0.6)$ \\
\hline Insurance & $2(0.4)$ \\
\hline Medical malpractice lawsuit & $2(0.4)$ \\
\hline Total & $535(100)$ \\
\hline
\end{tabular}

ty-related content in Korean available on YouTube is surgeryrelated information uploaded by medical doctors and clinics. The second most common type of content related to patient experiences, uploaded by personal channels. This content represented $9.7 \%(n=52)$ of all the uploaded content on the subject. This was followed by content relating to pre- and postoperative portrait $(6.9 \%, \mathrm{n}=37)$ and patient experiences $(5.8 \%, \mathrm{n}=31)$, both uploaded by medical doctors and clinics (Fig. 2).

Regardless of the quantity of the contents, the most-viewed and the third most-viewed videos with more than 2 million and 0.8 million views respectively are about patient experiences uploaded by personal channels. Both demonstrated the entire steps of aesthetic surgery, from in-office consultation to postoperative care. The second most-viewed video was a scene of a TV program, which was uploaded by one of the biggest broadcasters in South Korea. Notwithstanding its high proportion in the

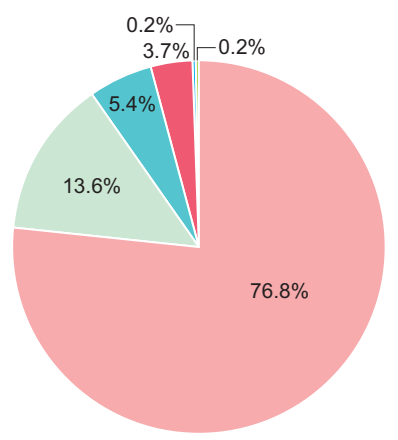

Medical doctor/clinic $(n=411)$ Personal $(n=73)$

$\square$ Content creator $(n=29)$

$\square$ Others $(n=20)$

$\square$ Oriental medicine doctor $(\mathrm{n}=1)$ $\square$ Lawyer $(n=1)$

Fig. 1. Types of uploader.

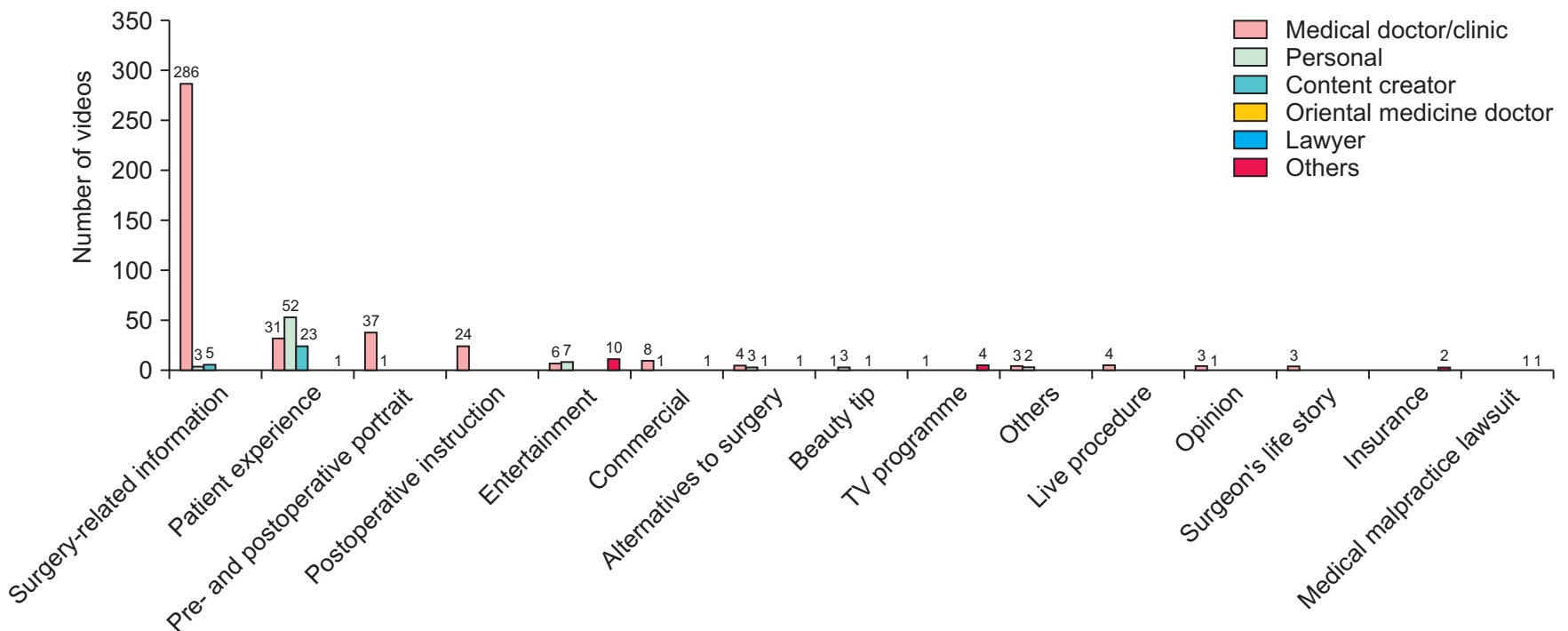

Fig. 2. Number of videos in each content type by type of uploader. 
Table 2. Top 10 most-viewed videos

\begin{tabular}{|c|c|c|c|c|c|}
\hline No. & Title & Content type & Type of uploader & Uploader (no. of subscriber) & View \\
\hline 1 & Fail to resist getting double eyelid surgery & Patient experience & Personal & Jo Doopal $(399,000)$ & $2,030,000$ \\
\hline 2 & $\begin{array}{l}\text { Yoo Hye-jung received a direct phone call from her } \\
\text { doctor after double eyelid surgery (anyone who } \\
\text { can hold laugh lol) }\end{array}$ & TV programme & Others & $\begin{array}{l}\text { KBS Entertain: } \\
\text { Kkalkkal TV }(379,000)\end{array}$ & 920,000 \\
\hline 3 & $\begin{array}{l}\text { I think I'm screwed./double eyelid surgery VLOG / } \\
\text { the surgery day 18th day }\end{array}$ & Patient experience & Personal & Huoney $(95,500)$ & 850,000 \\
\hline 4 & $\begin{array}{l}\text { ENG) [Pranks] Boyfriend is furious with double } \\
\text { eyelid makeup !? w w w }\end{array}$ & Entertainment & Others & YPTV $(253,000)$ & 700,000 \\
\hline 5 & $\begin{array}{l}\text { I have double eyelids now! Real review of double } \\
\text { eyelid surgery to untie the stitches }\end{array}$ & Patient experience & Personal & YU JEONG $(333,000)$ & 510,000 \\
\hline 6 & $\begin{array}{l}\text { Four reasons for failure of eye surgery, including } \\
\text { double eyelid surgery \#Eyes correction \#Double } \\
\text { eyelids \#lateral canthoplasty \#double eyelid } \\
\text { surgery edema [Gangnam Sister] }\end{array}$ & $\begin{array}{l}\text { Surgery-related } \\
\text { information }\end{array}$ & Content creator & Gangnam Unni TV $(100,000)$ & 430,000 \\
\hline 7 & $\begin{array}{l}\text { [Cultwo Show 7th UCC] Excellent prize double } \\
\text { eyelid surgery (Park Geun-tae) }\end{array}$ & Entertainment & Others & SBS Radio $(749,000)$ & 410,000 \\
\hline 8 & $\begin{array}{l}\text { A must-see video three times before double eyelid } \\
\text { surgery.zip \#inline \# outline \#in-outline | Plastic } \\
\text { Surgeon I know Ep.8 }\end{array}$ & $\begin{array}{l}\text { Surgery-related } \\
\text { information }\end{array}$ & $\begin{array}{l}\text { Medical doctor/ } \\
\text { clinic }\end{array}$ & $\begin{array}{l}\text { Plastic Surgeon I know } \\
(\mathrm{N} / \mathrm{A})\end{array}$ & 370,000 \\
\hline 9 & $\begin{array}{l}\text { Real review video of double eyelid surgery!/swelling } \\
\text { care/Recommendation of clinic for double eyelid } \\
\text { surgery }\end{array}$ & Patient experience & Personal & Lime Seula $(64,000)$ & 290,000 \\
\hline 10 & $\begin{array}{l}\text { (Double eyelid surgery/lateral canthoplasty/natural } \\
\text { adhesion/eye correction review \#1) Day to 6th day } \\
\text { of real review of eye correction/natural adhesion/ } \\
\text { lateral canthoplasty }\end{array}$ & Patient experience & Personal & Verena $(2,580)$ & 280,000 \\
\hline
\end{tabular}

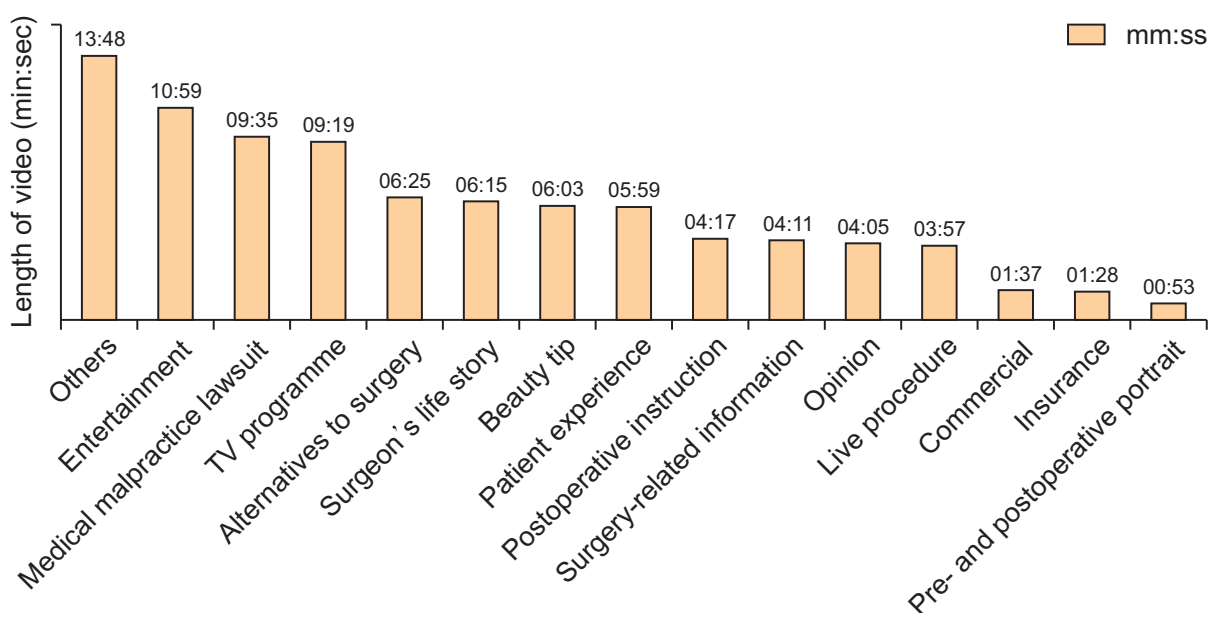

Fig. 3. Average length by content type.

types of uploaders, there was only one video in the list of the ten most-viewed videos uploaded by a medical doctor (Table 2).

The average length of the collected videos was 4 minutes and 46 seconds. The longest content type in average length was "others" (13 minutes 48 seconds), which was due to the low number of videos in this category and there being a one-hour video accusing the "ghost-surgeon" issue in Korean. Surgeryrelated information and patient experiences, which are the two dominant types quantitatively, had average lengths of 4 minutes and 11 seconds and 5 minutes and 59 seconds, respectively (Fig. 3).

\section{Discussion}

The results of this research found YouTube to be actively uti- 
lized by aesthetic surgeons in South Korea, making the content of these videos highly reliable. Further, there is a considerable amount of content uploaded by patients, helping other patients learn regarding what to expect from such procedures.

More than 2 billion users view YouTube videos every month. YouTube is available in more than 100 countries in 80 different languages [8]. As there are many people who use YouTube, there are diverse types of content available on it, including content relating to medical information. However, due to its feature that anyone can upload any information on YouTube, the credibility of information has been actively debated. Lee et al. [9] argue that to distinguish false information on social media, it is necessary to understand the source of information and how it is spread. Metzger et al. [10] found in their research that social data pooling, personal opinion testimony, supporter endorsements, and interpersonal resource sharing to have a significant impact on how people evaluate the credibility of information found on the Internet.

Ben Naftali et al. [11] found that only $13 \%$ of the total 300 videos in English that appeared on YouTube for the search term "plastic surgery" had been uploaded by plastic surgeons. A majority of these videos (66\%) were uploaded by company. In contrast, three-fourths of the videos in Korean that appeared for the search term "double eyelid surgery" had been uploaded by medical doctors or clinics (Fig. 1), leading to the interpretation that a majority of these videos carry lower risks of misconception and thus can be considered safe. However, since the average length of videos relating to surgery-related information is approximately 4 minutes, the information contained in these videos might not be rich (Fig. 3).

While approximately three-quarters of the collected videos had been uploaded by medical doctors, only one video from the specific category of uploaders made it to the ten most-viewed videos list (Table 2). The respective surgery-related video posted by a medical doctor garnered 370 thousand views. Furthermore, the uploaders with the most views have one common feature: all of them have a comparably high number of subscribers, an average of 263,000 subscribers (Table 2). This shows that one's influence plays a more crucial role in attracting the public on social media platforms, more than one's professionalism in the field. Thus, to improve the value of YouTube content, in terms of educational and promotional tools, it is necessary to find a way to satisfy the attractiveness and educational aspects of cosmetic surgery-related content on YouTube.

Interestingly, there is a YouTube channel that specializes in patient review. It has more than 50,000 subscribers and an aver- age view count of more than 5,000. They show every procedural step of the surgery with different patients in each episode [12]. However, as per the Medical Service Act of South Korea, "no person who is not medical personnel shall run an advertisement for medical services, which is referring to acts of indicating or giving information on medical services, institutions, personnel to consumers by means of newspapers, magazines, the internet, etc." [13].

Four of the $535(0.7 \%)$ videos contained clippings of live surgery (Table 1). All of these videos had been uploaded by medical doctors (Fig. 3). However, according to the medical legislation (Medical Service Act 2020), advertisements with any content that directly exposes medical treatment, such as the scene of the operation, are forbidden. The Enforcement Decree of Medical Service Act specifically prohibits "advertising by posting videos or photographs which the general public feel disgusted at, such as those showing the scenes of operations of patients performed by medical personnel, or the affected parts, etc. of patients" [14]. Since the word "feeling disgusted" is fairly subjective, it is hard to clarify the legality of the term. Although the South Korean law clearly prohibits the showing of scenes of operations, YouTube the one of the biggest online video-sharing platforms does not have any specific regulation differentiated by countries. It has only general regulations prohibiting the uploading of footages or imagery showing bodily fluids, such as blood or vomit, with the intent to shock or disgust viewers [15].

Further, newspapers, including online newspapers, magazines, and social media platforms with more than 100,000 daily users on average, etc., are subjected to the Deliberation of Medical Advertisement by the Korean Medical Association [13]. Nonetheless, because of comparable newness and difficulties in accessing user data, the contents on social media platforms such as YouTube are not effectively monitored. Thus, there is a need for a specific guideline to apply regulations on social media platforms.

As this study analyzed only the contents uploaded in South Korea, only Korean were investigated. Videos made in other languages were excluded. Due to the irregular availability of content on YouTube, the 5 videos removed during the review period were excluded from analysis. Moreover, as the nature of the videos available in Korean was significantly different from the nature of videos available in English, a modified criteria of classification that Almarghoub et al. [4] used in their research were used as the starting point for classifying content in the field of cosmetic surgery.

This study did not evaluate the quality of content. However, 
since there has not been any research that has analyzed aesthetic surgery-related content on YouTube in South Korea, this study has attempted to help people understand the conditions related to Korean cosmetic surgery on YouTube.

\section{Conflicts of interest}

The authors have nothing to disclose.

\section{References}

1. WISEAPP. App that Koreans use the most [Internet]. Seoul: WISEAPP; c2020 [cited 2020 Aug 11]. Available from: http:// naver.me/xFHKNIae.

2. WISEAPP. Video app that Koreans use the longest time [Internet]. Seoul: WISEAPP; c2020 [cited 2020 Aug 11]. Available from: http://naver.me/xQxyg3ll.

3. NASMEDIA. 2020 NPR summary report [Internet]. Seoul: NASMEDIA; c2020 [cited 2020 Aug 11]. Available from: https://www.nasmedia.co.kr/\%EC\%A0\%95\%EA\%B7\%B0\%EB\%B3\%B4\%ЕA\%B3\%A0\%ЕC\%84\%9C/2020\%ЕB\%85\%844\%ЕC\%9B\%94-2020-npr-\%EC\%9A\%94\%EC\%95\%BD\%ЕВ\%В3\%B4\%ЕA\%В3\%А0\%ЕC\%84\%9C/.

4. Almarghoub MA, Alghareeb MA, Alhammad AK, Alotaibi HF, Kattan AE. Plastic surgery on YouTube. Plast Reconstr Surg Glob Open 2020;8:e2586.

5. Patel A, Gemmiti AL, Ata A, Jun B, Johnson P. Abstract: can you trust what you watch? - an assessment of the quality of information about aesthetic surgery available on YouTube. Plast Reconstr Surg Glob Open 2017;5(9 Suppl):45-6.

6. Ward B, Ward M, Nicheporuck A, Alaeddin I, Paskhover B. Assessment of YouTube as an informative resource on facial plastic surgery procedures. JAMA Facial Plast Surg 2019;21:756.

7. Gallup. Perception of appearance and plastic surgery - com- parison of 1994/2004/2015/2020 [Internet]. Seoul: Gallup; c2020 [cited 2020 Aug 10]. Available from: https://www.gallup. co.kr/gallupdb/reportContent.asp?seqNo=1097.

8. YouTube. YouTube for press [Internet]. San Bruno, CA: YouTube; c2020 [cited 2020 Aug 25]. Available from: https://www. youtube.com/about/press/.

9. Lee G, Sohn S, Jeong E. Network analysis on the diffusion of fake medical information on YouTube: a case study of a fake news "inserting an onion in the ear to heal earaches". Health Commun Res 2018;17:97-129.

10. Metzger MJ, Flanagin AJ, Medders RB. Social and heuristic approaches to credibility evaluation online. J Commun 2010;60:413-39.

11. Ben Naftali Y, Duek OS, Rafaeli S, Ullmann Y. Plastic surgery faces the web: analysis of the popular social media for plastic surgeons. Plast Reconstr Surg Glob Open 2018;6:e1958.

12. BBEU TV [Internet]. San Bruno, CA: YouTube; [cited 2020 Aug 13]. Available from: https://www.youtube.com/channel/ UC6hkgThmmzaVp86BupHzDHA.

13. National Law Information Center. Medical service act 2020 c.5. a.56. [Internet]. Sejong: Korea Ministry of Government Legislation; c2020 [cited 2020 Aug 14]. Available from: http://www.law.go.kr/LSW/eng/engLsSc. do? menuId=2\&query=MEDICAL\%20SERVICE\%20 ACT\#liBgcolor24.

14. National Law Information Center. Enforcement decree of medical service act 2020. a.23. [Internet]. Sejong: Korea Ministry of Government Legislation; c2020 [cited 2020 Aug 14]. Available from: http://www.law.go.kr/LSW/lsInfoP.do?lsiSeq $=214803 \&$ ancYd $=\& a n c N o=\&$ efYd $=20200228 \&$ nwJoYnInfo $=Y \&$ ancYnChk=0\&efGubun=Y\&vSct=*\#0000.

15. YouTube. YouTube policies [Internet]. San Bruno, CA: YouTube; c2020 [cited 2020 Aug 17]. Available from: https://support.google.com/youtube/topic/2803176?hl=en-GB\&ref_ topic $=6151248$. 